\title{
Usando Smartphone e Realidade aumentada para estudar Geometria espacial
}

\author{
Alex de Cassio Macedo - UFPR - proflecao@ gmail.com; \\ João Assumpção da Silva - ISEPE - jasgtba@ gmail.com; \\ Tiago Martinuzzi Buriol - UFSM - tiago.buriol@ufsm.br.
}

\begin{abstract}
RESUMO: Neste trabalho é apresentado o desenvolvimento do aplicativo AppiRAmide para o estudo de Geometria espacial por meio de Realidade Aumentada usando dispositivos móveis. Adicionalmente, foi conduzida uma aula experimental com a aplicação de uma sequência didática usando o material impresso especialmente desenvolvido para uso com o aplicativo. $\mathrm{O}$ experimento foi conduzido em uma aula sobre pirâmides para uma turma de Ensino Médio. A partir de questionários e observações foram levantadas as impressões desses alunos sobre o aplicativo, o material impresso e a sequência didática. A análise dos resultados obtidos mostrou que os alunos reconheceram o AppiRAmide como uma ferramenta eficiente na visualização tridimensional interativa, na aprendizagem de Geometria espacial, na motivação e ainda, complementa satisfatoriamente o material didático impresso.
\end{abstract}

Palavras chave: Realidade Aumentada, Geometria espacial, Dispositivos móveis.

\section{Using Smartphone and Augmented Reality for Spatial Geometry Study}

\begin{abstract}
This work presents the development of AppiRAmide, an app for spatial geometry study by Augmented Reality in mobile devices. In addition, a experimental lesson class was conducted with the app using a didactic sequence with the printed material specially developed for use among the app. The experiment was conducted in a lecture about pyramids in a high school class. From the questionnaires results and from observations obout the students behavior, the app and the printed materials and the teaching sequence acceptance was assessed. The analysis of results showed that students recognized the AppiRAmide as an efficient tool for interactive three-dimensional visualization, spatial geometry learning, motivation and also as a successfully complements for the printed material.
\end{abstract}

Keywords: Augmented Reality, Spatial Geometry, Mobile.

\section{Introdução}

Tendo em vista os avanços tecnológicos ocorrido nos últimos anos, parece pouco sensato pensar em ensino sem pensar em usufruir dos benefícios proporcionados pelas novas tecnologias digitais disponíveis. Tornou-se evidente a necessidade de se repensar práticas pedagógicas de forma a agregar essas tecnologias ao dia a dia de sala de aula de maneira efetiva e alinhada aos objetivos didáticos. Existem, nesse sentido, alguns desafios relativos às mudanças culturais e à capacitação de profissionais de educação, que precisam ser vencidos para que seja possível, enfim, usufruir plenamente de todo potencial que tais tecnologias oferecem como suporte para o processo de ensino e aprendizagem.

Utilizando computação gráfica em dispositivos móveis, como tablets e smartphones, por exemplo, o estudo de Geometria espacial, poderia ser mais atraente e eficaz. Atualmente, o aumento da capacidade de processamento gráfico desses dispositivos tem permitido ampliar o acesso às tecnologias como Realidade Virtual e Realidade Aumentada. Jogos, vídeos e aplicativos usando tais tecnologias se popularizam cada vez mais. Sem dúvida esses recursos seriam de grande valor para aqueles alunos que apresentam dificuldades em visualizar figuras tridimensionais que são representadas nos livros didáticos de forma plana. Essas dificuldades fazem com que muitos alunos não compreendam por completo os conceitos, propriedades e 
demonstrações geométricas Assim, é possível que aulas tradicionais, expositivas e dialogadas, tendo como únicos recursos, lousa, giz e livro didático não sejam suficientes para que esses alunos possam compreender os conceitos geométricos propostos (Grillo, 2014).

Considerando, portanto, as potencialidades das tecnologias digitais atuais, incluindo a comunicação, processamento numérico e a computação gráfica, o desafio é aliar computador, celular, tablet, etc., ao processo ensino aprendizagem como objetos educacionais capazes de aperfeiçoar as aulas e os recursos. É preciso buscar meios de usufruir dessas ferramentas e criar métodos de apresentação de conteúdo que possam contribuir para assimilação de conceitos e na potencialização dos métodos de estudo dos alunos e das metodologias de ensino dos professores. Esse é um grande desafio, pois a produção de conteúdos digitais interativos e alinhados com uma sequência didática específica demanda considerável volume de trabalho e conhecimentos que podem incluir programação de computadores.

Neste trabalho é apresentado o desenvolvimento um aplicativo baseado em Realidade Aumentada para o estudo de pirâmides, juntamente com uma sequência didática e um experimento envolvendo sua utilização em sala de aula. A tecnologia de RA permite utilizar dispositivos móveis para visualizar e interagir com objetos geométricos virtuais. Assim, o presente trabalho aborda a questão do uso de novas tecnologias para o ensino de uma maneira prática. Por meio de um experimento realizado em sala de aula, traz à discussão o uso de dispositivos móveis em sala de aula e da tecnologia RA como recurso de suporte à aprendizagem de tópicos de geometria. Foi desenvolvido o aplicativo AppiRAmide, para sistemas Android, que, a partir do conteúdo Pirâmides presente na seção Geometria Espacial de manuais didáticos tradicionais, fornece animações, simulações e cenas que interagem com um material didático impresso próprio, também desenvolvido no âmbito desta pesquisa.

Por fim, com o experimento realizado em sala de aula, buscou-se levantar dados que possam reafirmar a potencialidade do uso de tais ferramentas e tecnologias nesse ambiente. Um relato da experiência envolvendo a aplicação da sequência didática em uma turma de Ensino Médio é apresentado. Os resultados obtidos nesta intervenção visam contribuir com a discussão acerca do uso de tecnologias em sala de aula em especial a da RA fornecendo subsídios pedagógicos e motivacionais para tanto.

\section{As novas tecnologias na Educação Matemática.}

As Orientações Curriculares para o Ensino Médio são documentos produzidos pelo Ministério da Educação que têm como objetivo contribuir para o diálogo entre professor e escola sobre a prática docente. Nesse documento, as novas Tecnologias de Informação e Comunicação (TICs) contemplam o ensino de matemática sob duas dimensões: "a matemática como ferramenta para entender a tecnologia, e a tecnologia como ferramenta para entender a matemática" (Brasil, 2006, p. 8). No contexto desse trabalho essas duas dimensões estão inseridas, pois um conhecimento matemático foi necessário para desenvolver o aplicativo AppiRAmide, o qual será utilizado para o aprendizado de sólidos geométricos (pirâmides).

Por sua vez, a tecnologia, quando utilizada como ferramenta para entender a matemática, pode ser percebida nos aplicativos e programas que são utilizados pelo aluno na resolução de problemas, no teste de hipóteses e na criação de suas próprias conjecturas. Portanto o fazer matemático através do uso das tecnologias deve provocar certa reflexão, e, sobretudo a organização consciente do conhecimento. Assim, o aluno pode ser capaz de criar para si um ambiente de conjecturas, argumentações e demonstrações acerca do objeto em estudo. (D'Ambrosio, 1996, p. 19).

De fato, a disciplina de Matemática tem especial conexão com a temática das tecnologias digitais, uma vez que fornece conhecimentos fundamentais para o seu desenvolvimento em diversas modalidades e aplicações (Kalinke, Mocrosky E Estephan, 2013). Uma destas modalidades, a qual é tema deste trabalho, possibilita criar cenas em que objetos virtuais são inseridos em um cenário real, capturados pela câmera de computadores ou dispositivos móveis. É a chamada Realidade Aumentada (RA).

Ao "misturar" o mundo virtual com o real é possível criar formas de interação com objetos que só estão limitados à nossa imaginação. A possibilidade de visualizar, explorar 
livremente vários pontos de vista e interagir com objetos virtuais tridimensionais pode sugerir inúmeros benefícios potenciais para o ensino de sólidos geométricos. $\mathrm{O}$ uso dessas tecnologias oferece aos alunos a possibilidade de explorar tópicos da disciplina de matemática de forma mais intensa, desenvolvendo sua intuição e sua consciência dos conteúdos.

\section{Realidade Aumentada para o Ensino e Aprendizagem de Matemática}

A tecnologia da RA se constitui de técnicas computacionais que a partir de um dispositivo tecnológico, geram, posicionam e mostram objetos virtuais integrados a um cenário real. Assim, o usuário mantém o senso de presença no mundo real, o que não ocorre, por exemplo, em realidade virtual. Este mecanismo enfatiza a qualidade das imagens e a interação do usuário com esses objetos em tempo real. O tipo de interação mais comum em Realidade Aumentada é aquela em que o usuário se move livremente em torno do objeto, visualizando-o sob diferentes pontos de vista. (Kirner e Tori, 2006).

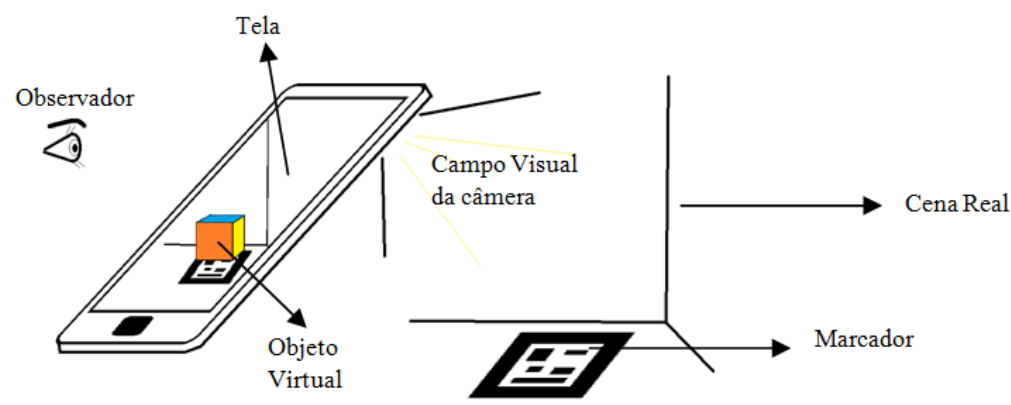

Figura 1- Funcionamento da Realidade Aumentada em Dispositivos móveis.

Basicamente, o funcionamento deste sistema (Figura 1) constitui na apresentação de um marcador (imagem que serve como referência para a posição do objeto virtual) no campo visual da câmera. Em seguida, o sistema, através de um aplicativo, detecta e rastreia os marcadores, projetando os objetos virtuais 3D ou qualquer outra mídia sobre a marca, e este por sua vez pode ser visualizado simultaneamente ao ambiente pelo usuário (observador) via tela do dispositivo. Um marcador geralmente é uma imagem geométrica que serve como um código e, também, uma referência para a posição e orientação da câmera.

Para Faust, et al. (2011), o "boom" da RA em dispositivos móveis se deve ao aumento da capacidade de processamento gráfico desses aparelhos, a popularização de tablets e smartphones, o custo benefício deles e o potencial de transmissão de dados (aumento da banda) de internet favorecendo sua possibilidade colaborativa e distribuição.

Para a área de ensino-aprendizagem, o que se observa é que a tecnologia de RA apresenta-se madura o bastante, sendo capaz de oferecer características como alto grau de manutenção do interesse e facilitação da compreensão dos conceitos estudados, a partir da possibilidade de interação direta com seus objetos representativos. O aspecto lúdico intrínseco da utilização desta tecnologia também é um fator a destacar (Forte e Kirner, 2009).

As aplicações de RA possuem a capacidade de usar objetos físicos para manipular as informações virtuais de uma maneira intuitiva. Desta maneira, pessoas sem grande conhecimento de computação podem ter uma experiência de interação com a aplicação, sem mouse ou teclado para serem operados. Esta propriedade possibilita mesmo aos alunos mais jovens, o contato e a autonomia com a tecnologia e, assim, participarem de uma rica experiência de aprendizado (Billinghurst, 2002).

Nos últimos anos, diversos trabalhos sobre esse tema têm sendo publicados no Brasil, considerando especificamente o ensino de matemática destacamos três trabalhos que serão comentados a seguir.

Lemos e Carvalho (2010) publicaram um artigo no qual mostraram o desenvolvimento e a utilização de um software baseado em RA para apoio ao ensino da relação de Euler chamado SISEULER ${ }^{I}$. Os autores concluíram, a partir da utilização em sala de aula, que o SISEULER 
estimula o processo investigativo dos alunos e atua como fator motivador intensificando o interesse dos alunos pelo assunto, tornando o processo ensino aprendizagem do conteúdo mais valoroso.

Já Leitão (2013) propõe a criação de um jogo digital para dispositivos móveis que visa ajudar os alunos a adquirirem conhecimentos através de RA. Os resultados obtidos na pesquisa mostraram que o jogo possui a capacidade de despertar curiosidade, motivação e iniciativa nas crianças, devido ao seu caráter envolvente e interativo e ainda, do ponto de vista pedagógico, ajudou-os a alcançar as competências que o jogo visava desenvolver: capacidade de visualização; a compreensão de propriedades dos sólidos geométricos e a familiarização com o vocabulário da geometria.

Recentemente, Almeida e Santos (2015) publicaram um artigo que mostra como o uso da RA pode contribuir para melhoria no ensino do conteúdo do Teorema de Tales. Para tanto, os autores elaboraram uma atividade por meio do Software Aumentaty Author ${ }^{2}$, a qual foi aplicada pelo professor regente a 29 alunos da $8^{\text {a }}$ Série do Ensino Fundamental. As conclusões foram obtidas por meio de questionários aplicadas aos alunos e professores antes e depois da realização da atividade. Tanto os discentes como o docente consideraram que o uso dessa tecnologia melhora o processo de ensino aprendizagem, permitindo criar um ambiente mais atrativo em sala de aula, motivador e inovador.

\section{AppiRAmide: concepção e desenvolvimento}

O AppiRAmide é um aplicativo para dispositivos móveis que utiliza a tecnologia de RA para auxiliar o estudo de pirâmides. O conteúdo do aplicativo complementa e enriquece o conteúdo impresso, especialmente preparado para a utilização em conjunto. $\mathrm{O}$ aplicativo e seus complementos foram desenvolvidos durante o curso Especialização em Matemática Computacional aplicado à Educação, oferecida pelo Instituto Federal do Paraná - IFPR, campus Paranaguá. Assim, o produto desse trabalho consiste do desenvolvimento do aplicativo, do material didático impresso e de uma sequência didática específica para sua utilização. Além disso, o aplicativo foi testado em uma aula experimental em que informações foram coletadas para a sua avaliação preliminar. Os resultados desse experimento estão descritos na Seção 5.

$\mathrm{O}$ aplicativo funciona projetando em uma cena real, capturada pela câmera e visualizada na tela do dispositivo, modelos virtuais 3D animados que auxiliam no estudo de pirâmides. Os objetos virtuais aparecem na cena quando um marcador contido no material impresso aparece na tela. Ao todo são seis diferentes cenas contemplando tópicos como a definição formal de pirâmide, elementos, classificação, relações métricas, planificação, cálculo de áreas e volume.

Diversas são as plataformas que possibilitam a criação deste tipo de aplicação. Nesse trabalho optou-se por um conjunto de softwares e ferramentas com base em características como gratuidade da licença de uso, documentação e nível de conhecimento técnico exigido. Os programas utilizados foram: Artoolkit ${ }^{3}$, Unity $3 d^{4}$, Blender ${ }^{5}$, Paint e um gerador de marcadores online ${ }^{6}$.

Antes de iniciar a implementação das cenas foram definidos, na pré-produção, quais conceitos seriam animados e simulados, quais objetos 3D seriam utilizados, como seriam as animações e simulações e ainda, como seria o layout de tela. A implementação consistiu na modelagem dos objetos da cena, criação dos marcadores, programação das cenas e das animações, criação dos layouts na Unity, compilação e finalmente testes. Esses passos foram repetidos para cada uma das cenas criadas e devidamente testadas em um tablet. Como resultado, o aplicativo gera na tela do dispositivo, a partir de marcadores preparados para tal, as 6 cenas que exploram definições, elementos e demonstrações utilizados no estudo de pirâmides

A cena 1 (Figura 2a) é uma animação para auxiliar o entendimento da definição de pirâmides. Na cena 2 (Figura 2b), é mostrada uma pirâmide virtual com a indicação de seus elementos. A cena 3 (Figura 2c) é um jogo de perguntas e respostas sobre o nome das diferentes classificações de pirâmides. Já a cena 4 (Figura 2d) é um simulador, onde uma pirâmide, a partir de botões na tela, gira entorno dos seu eixo, além disso, é possível visualizar as relações métricas, planificar e ainda desabilitar a visualização de arestas e faces. A cenas 5 (Figura 2e) mostra uma animação da demonstração de área lateral e total de uma pirâmide e das fórmulas 
que calculam estas medidas. E por fim, na cena 6 (Figura 2f) uma animação da demonstração do volume de uma pirâmide e da fórmula que calcula esta medida é apresentada quando um botão na tela é pressionado.
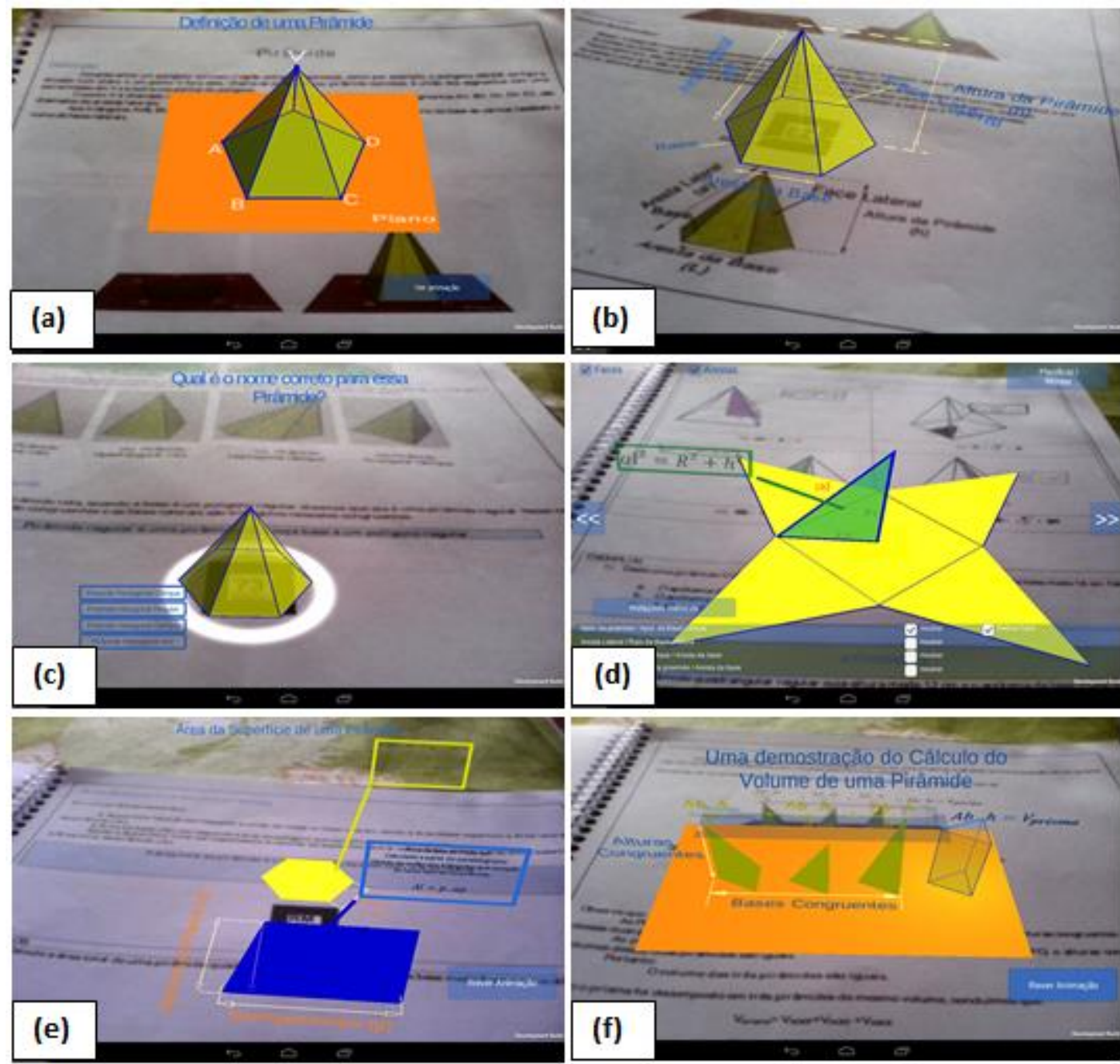

Figura 2 - Visualização das cenas do AppiRAmide na tela do dispositivo móvel.

\section{Experiência em sala de aula}

O AppiRAmide foi utilizado pela primeira vez, em sala, com alunos do Ensino Médio do curso técnico em Mecânica do Instituto Federal do Paraná Campus Paranaguá, por meio de uma aula experimental com uma sequencia didática devidamente preparada para tanto.

Para esta intervenção, foi necessário preparar um material didático que contemplasse o conteúdo de pirâmide, tradicionalmente trabalhados no Ensino Médio e que fosse capaz de correlacionar o conteúdo formal aos marcadores e cenas do AppRAmide de forma a organizar as interações com a teoria e os exercícios propostos, estes por sua vez, foram baseadas nos livros didáticos comumente utilizados no Ensino Médio.

Foi necessário ainda, para melhor coleta dos dados a elaboração de dois questionários, um inicial e outro final. Para garantir um registro mais completo, toda a aula foi gravada com um aparelho de áudio digital, para posterior análise da aula e dos comentários.

O questionário inicial teve como objetivo verificar:

(1) qual o nível de conhecimento dos alunos quanto ao conceito de Pirâmides e a relação entre visualização de objetos reais e figuras utilizadas em livros didáticos. A primeira questão foi aberta e os alunos poderiam expressar o que sabia sobre o conceito de pirâmides e já na 
questão dois foram apresentados sólidos didáticos construídos em acrílico para que os alunos correlacionassem com figuras impressas na folha do questionário.

(2) Analisar o uso de dispositivos móveis em sala de aula e se tinham conhecimento ou contato com a tecnologia da Realidade aumentada. As questões 3,4 e 6 foram objetivas, já a questão 5 era aberta e o aluno poderia expressar sua opinião acerca do uso do celular em sala.

No questionário final, as questões versaram sobre os aspectos motivacionais, pedagógicos e funcionais do aplicativo, onde cada participante pode avaliar a aula, o material e o aplicativo com suas próprias impressões. Em cada item o aluno deveria atribuir uma nota de 1 a 5 onde refletisse o nível de aceitação sendo 1 o nível mais baixo de aprovação e 5 o máximo.

Foram convidados todos os 25 alunos de uma turma de $3^{\circ}$ ano para a atividade, porém compareceram e foram volutários um grupo de 11 alunos sendo, 2 meninas e 9 meninos. Os participantes foram convidados a se dirigirem ao LIFE - Laboratório Interdisciplinar de Formação de Educadores a fim de participarem da aula experimental e espontaneamente contribuir com a pesquisa fornecendo suas impressões e consentindo com a gravação em áudio das discussões.

A aula experimental teve uma duração de 3 aulas de 50 min e ocorreu em 3 momentos distintos;

(1) Questionário Inicial (duração cerca de 10min), onde os alunos responderam por escrito individualmente a 6 perguntas.

(2) Aula propriamente dita, onde deforma expositiva, com auxílio de um Datashow o professor conduzia as explicações e convidava os alunos a utilizarem o AppiRAmide, estimulando as interações: aluno - aluno e aluno - material didático. Todos os alunos tinham disponíveis tablets com o AppiRAmide instalados e o material didático impresso.

(3) No questionário final os alunos receberam outra folha com as questões objetivas que norteavam a avaliação da atividade, sendo a última livre onde os alunos deveriam expressar livremente, de seu ponto de vista, pontos positivos e negativos com relação à atividade realizada.

\section{Análise e discussão dos resultados obtidos.}

Após a coleta dos dados dos questionários e a audição da aula gravada, foi possível sistematizar as respostas em gráficos, quadros e realizar a transcrição de falas relevantes ao que se pretende analisar.

Com relação aos resultados obtidos no questionário inicial podem-se destacar os seguintes aspectos:

Na questão 1 o objetivo era verificar qual conhecimento de pirâmide os alunos tinham, vale salientar que segundo a professora regente da turma eles ainda não tinham estudado este conteúdo no Ensino Médio, por este motivo a pergunta versava sobre a definição de pirâmides. O gráfico da Figura 3 sintetiza em grupos as respostas obtidas.

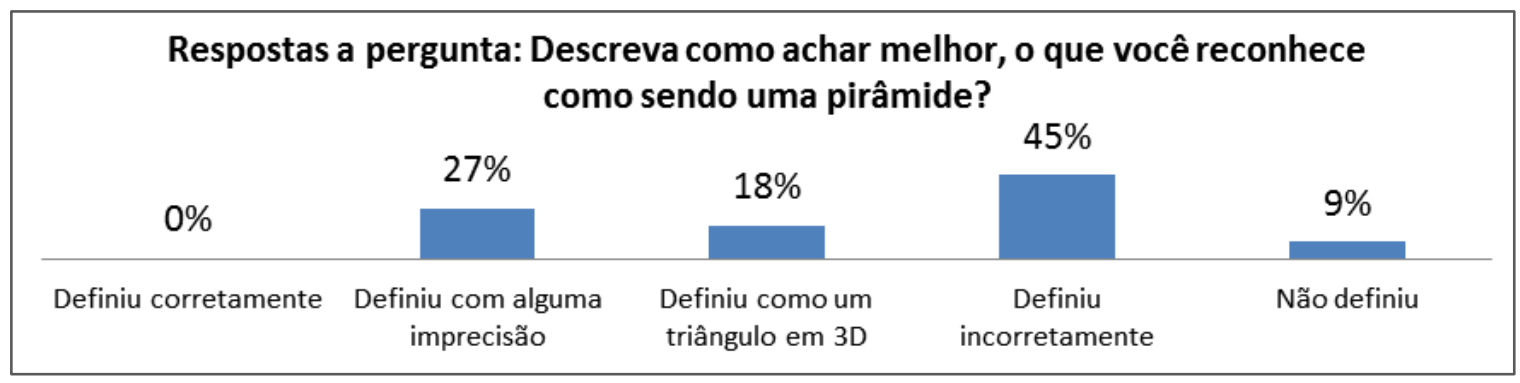

Figura 3 - Resultado apurando quanto às definições de pirâmide apresentada pelos alunos.

Nesta questão observou-se que nenhum aluno conseguiu definir corretamente uma pirâmide, porém alguns alunos curiosamente a definiram como um triângulo 3D, não faz parte deste trabalho discutir com relação à compreensão prévia que cada aluno tem dos conceitos de 
geometria, porém pode ser um indício de dificuldade na visualização de figuras $3 \mathrm{D}$, bem como a diferenciação entre figuras planas e espaciais.

Na questão 2 os alunos deveriam relacionar sólidos (reais) de acrílico colocados sobre uma mesa, com figuras que representavam pirâmides de forma plana, tal qual se apresentam nos livros didáticos. A partir das respostas obtidas foi possível perceber que $73 \%$ da turma conseguiu relacionar corretamente os itens, porém $27 \%$ dos alunos apresentam dificuldades de visualizar e relacionar os sólidos, real (3D) com os desenhos (2D).É importante destacar que durante a aplicação dos questionários os alunos tinham liberdade para se aproximar e visualizar da forma que quisesse antes de apresentar sua resposta.

As questões 3, 4 e 5 investigaram o quanto os alunos usam celular em sala de aula, em quais tipos de atividades de aprendizagem o celular é utilizado e qual a opinião em relação à possibilidade de uso do celular em sala. Por fim, a última pergunta (questão 6) do questionário inicial indagava quanto ao conhecimento que os alunos tinham com relação à tecnologia da Realidade Aumentada. Os gráficos (Figura 4) a seguir apresentam os resultados destas perguntas.

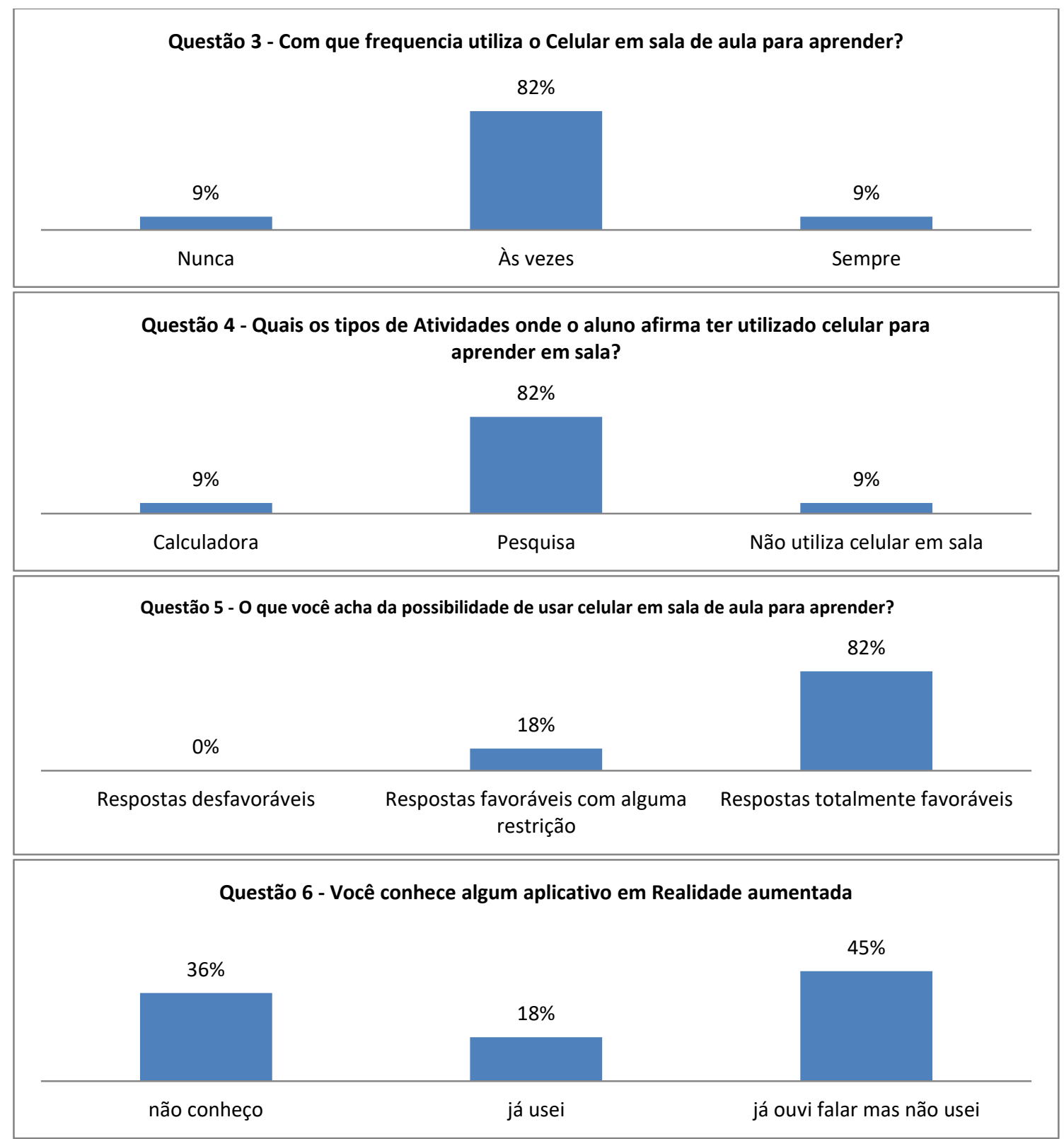

Figura 4: Resultado apurando nas questões 3,4,5 e 6 do questionário inicial. 
Os gráficos da Figura 4 mostram que a maioria dos alunos participantes, demostram uma boa receptividade quanto à inserção de dispositivos móveis nas aulas e apesar de conhecerem a RA, muitos ainda não tinham usado este tipo de aplicativo, o que reforça a ideia de que eles tratariam o AppiRAmide como uma novidade.

Por meio dos registros audiofônicos é possível perceber que os alunos tiveram um momento de euforia logo após o recebimento do material e as orientações sobre o uso do aplicativo, à medida que exploravam o material interagiam e comentavam o que descobriam. A princípio, a impressão era que eles não retomariam a concentração inicial no tema da aula, contudo, logo que o professor os convida-os ao inicio da aula, prontamente "largam" o tablet e se voltam a participar das explicações do professor. Percebe-se que apesar de ser uma novidade para a maioria dos alunos, o aplicativo não foi motivo de distração, aparentemente a condução da aula seguiu de forma adequada conforme a proposta.

Num dos momentos da aula que merece destaque, logo após o professor comentar a respeito da classificação das pirâmides e orientar que realizassem o jogo de perguntas e respostas "Qual o nome correto dessa pirâmide?" (cena 3 do AppiRAmide), um aluno fez o seguinte comentário: -"Legal! Agora que o professor explicou ali... como é o nome das pirâmides consegui responder mais rápido que a outra vez...".

Este comentário contribui com a ideia de que é possível articular o conteúdo e uma interação de formar motivar o estudo, uma das propostas desta pesquisa.

Os gráficos da Figura 5 sintetizam os resultados fornecidos pelos alunos no questionário final.
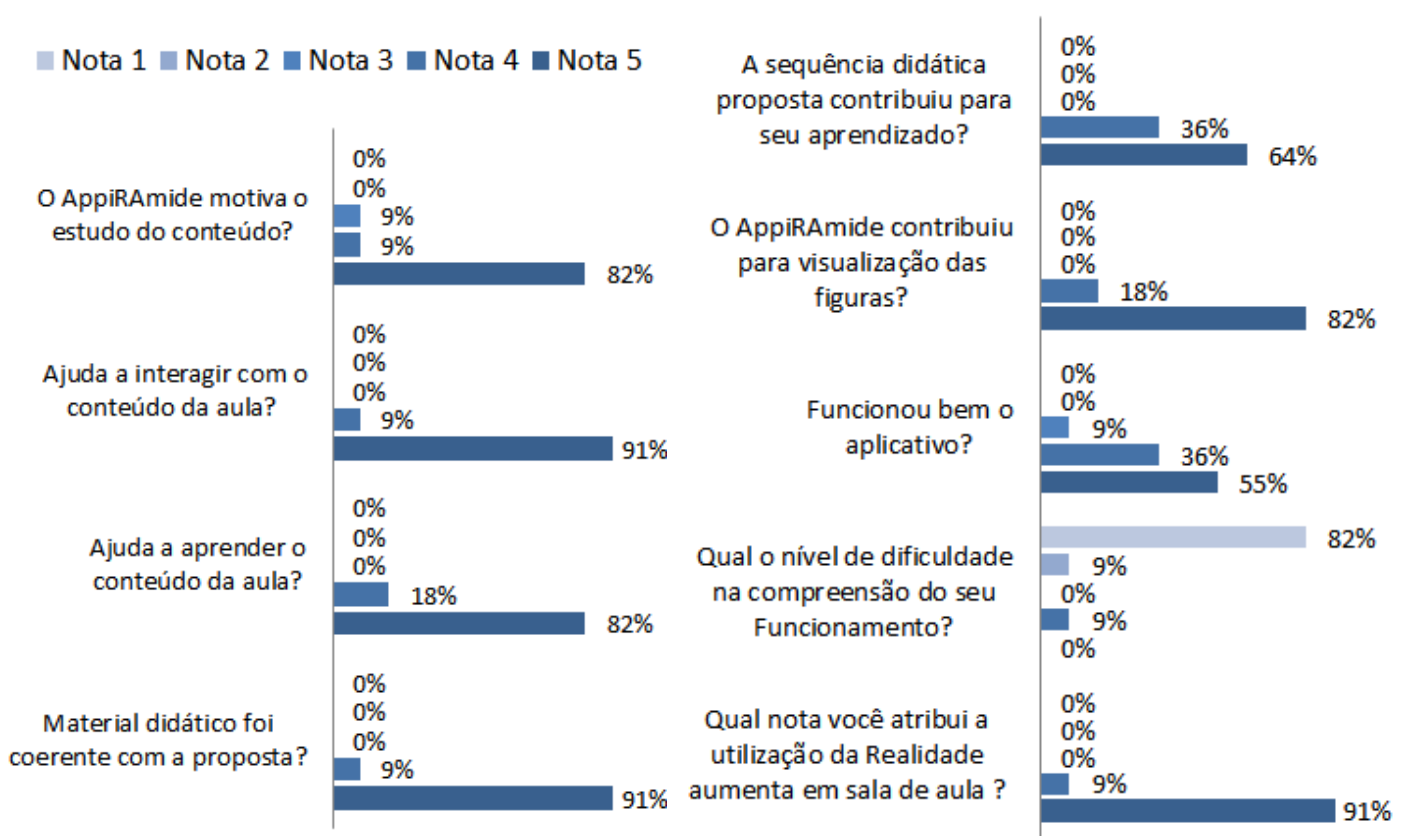

Figura 5 - Resultado apurando no questionário final.

Através dos gráficos apresentados (Figura 5) é possível perceber que a avaliação feita pelos alunos participantes de um modo geral foi positiva, as notas atribuídas quanto à motivação, interação e aspectos pedagógicos corresponderam em sua maioria no máximo de aprovação, já no aspecto relativo ao funcionamento do aplicativo, $55 \%$ dos alunos atribuíram nota 4 , o que mostra uma pequena frustração quanto à expectativa deles com relação a algumas cenas.

No questionário final, consta uma questão onde os alunos deveriam expressar livremente, de seu ponto de vista, pontos positivos e negativos com relação à atividade realizada. A Tabela 1 apresenta uma síntese dessas respostas. 
Tabela 1 - Pontos positivos e negativos apontados pelos alunos.

\begin{tabular}{|l|l|}
\hline Pontos positivos & Pontos negativos \\
\hline - Incentiva a aula & - Desvirtua momentos da aula. \\
- Proporciona uma aula diferente. & - Aumenta a possibilidade de o aluno ficar \\
- Melhora a visualização & jogando ao invés de estudar. \\
- Ajuda aprender formas Geométricas & - Deve-se melhorar a estética do aplicativo. \\
- Ajuda a entender o conteúdo & - Dispersa a atenção dos alunos. \\
- Chama mais a atenção à disciplina e melhora & - Atenção pode ficar presa ao aplicativo. \\
o rendimento escolar. & \\
- Torna a aula mais interessante. & \\
- Aula ficou mais funcional e menos cansativa. & \\
- Motivador e desperta o interesse no conteúdo. & \\
- Aumenta o interesse dos alunos. & \\
\hline
\end{tabular}

Por fim, o questionário permite na última questão que o participante deixe algumas observações que contribuíssem na pesquisa ou na melhoria do aplicativo. Segue algumas das observações (transcritas do questionário):-"Fazer para mais conteúdos",- "Muito bom o aplicativo", -"As teclas do jogo de perguntas e respostas são pequenas e próximas, difícil de apertar".- "Algumas vezes as animações se movimentam demais mesmo mantendo o aparelho imóvel.".

Esta ultima questões evidenciam a satisfação dos alunos com o aplicativo, ao mesmo tempo em que mostram sugestões para melhoramentos e indícios para novas pesquisas e experimentações.

\section{Conclusão}

Após as pesquisa e discussões realizadas, e ainda, os resultados obtidos foi possível concluir que o presente trabalho cumpriu seu objetivo de mostrar o desenvolvimento de um aplicativo de RA em dispositivos móveis para auxílio no aprendizado de sólidos geométricos e muito embora o número de alunos participantes seja relativamente pequeno, esta primeira experimentação forneceu diversos pontos que podem servir de estímulo a discussões, pesquisas e novas experimentações.

As análises realizadas apontaram para os seguintes aspectos; (1) Os alunos se mostraram receptivos quanto ao uso de dispositivos móveis em sala como recurso pedagógico. (2) A RA contribuiu na motivação e interação dos alunos com relação ao conteúdo da aula. (3) Alguns alunos reconheceram o AppiRAmide como uma ferramenta eficiente na visualização de objetos $3 \mathrm{D}$, e isso contribui a aprendizagem do conteúdo abordado.

Alguns erros foram levantados pelos participantes durante a utilização do AppiRAmide, os quais podem ser corrigidos em uma nova versão, tais como, (1) um layout pouco amigável, (2) os botões do jogo de perguntas e respostas e das animações são pequenos e de difícil toque e (3) instabilidade da imagem de algumas cenas. Mesmo com estes erros a utilização do aplicativo foi bem avaliada pelos participantes, o que sugere, que tais erros não comprometeram o aspecto pedagógico observado.

A RA, que foi objeto desse estudo, é mais uma possibilidade para utilização de dispositivos móveis em sala de aula como um recurso pedagógico. Ela por si só não resolverá todas as dificuldades inerentes ao processo ensino-aprendizagem, nem tampouco pode substituir a presença do professor em sala, mas se bem direcionada pode ser uma tecnologia promissora neste processo.

A expectativa é que os resultados deste trabalho contribuam na discussão relativa à inserção de novas tecnologias em sala de aula, ou seja, que os dispositivos móveis como notebook, smartphones, tablets e etc., sirvam de ferramentas para potencializar a construção de conhecimentos em sala de aula e não sejam considerados entraves para o desenvolvimento do 
aluno, ao passo que, os professores precisam ousar, pesquisar e experimentar novas formas de ensinar a partir de metodologias inovadoras.

\section{Referências bibliográficas}

ALMEIDA, M. L. D.; SANTOS, G. Realidade Aumentada na Educação. Revista Tecnologias na Educação, v. Ano 7, n. $\mathrm{n}^{\circ}$ 12, Julho 2015.Disponível em; <http://tecedu.pro.br/ano7numerovol12/> acesso em junho de 2016.

BILLINGHURST, M. Augmented Reality in Education. New Horizons for Learning, Seattle, Dezembro 2002. Disponível em:< goo.gl/5aRHhR > Acesso em: julho de 2016

BRASIL, M. Orientações Curriculares para o Ensino Médio: Ciências na natureza, matemática e suas tecnologias. Brasília: MEC/SEB, v. 1, 2006.

D'AMBROSIO, U. Educação Matemática: da teoria a prática. 20. ed. Campinas: Papirus, 1996.

FAUST, F. G. et al. Aplicações e Tendências da Realidade Aumentada no Desenvolvimento de Produtos. In: $8^{\circ}$ CONGRESSO BRASILEIRO DE GESTÃO DE DESENVOLVIMENTO DE PRODUTOS. Porto Alegra: 2011.

FORTE, C. E.; KIRNER, C. Software educacional potencializado com realidade aumentada para uso em matemática e física. Dissertação (Mestrado em Ciências da computação). Piracicaba: UNIMEP. 2009.

GRILLO, J. D. Atividades e Problemas de Geometria Espacial para o Ensino Médio. 2014. 124 f. Dissertação (Mestrado Profissional em Matemática em Rede Nacional - PROFMAT). São Carlos - SP: UFSCAR. 2014.

KALINKE, M. A.; MOCROSKY, L.; ESTEPHAN, V. M. Matemáticos, educadores matemáticos e tecnologias: uma articulação possível. Educação Matemática Pesquisa, São Paulo, v. 15, n. 2, pp. 359-378, 2013.

KIRNER, C.; TORI, R. Fundamentos da Realidade Aumentada. Cláudio Kirner;Romero Tori;Robson Siscouto.(Ed.) Fundamentos e Tecnologia da Realidade Virtual e Aumentada. Pré Simpósio SVR2006. Belém: SBC. 2006. p. 22-38.

LEITÃO, R. M. V. Aprendizagem baseada em jogos: realidade aumentada no ensino de sólidos geométricos. 2013. 77 f. Dissertação (Mestrado em Expressão gráfica e Audiovisual). Lisboa: Universidade Aberta. 2013.

LEMOS, B. M.; CARVALHO, C. V. D. A. Uso de realidade aumentada para apoio ao entendimento da relação de Euler. Novas Tecnologias na Educação, Porto Alegre, v. V. 8 , n. $\mathrm{N}^{\mathrm{o}} 2$, julho 2010.

\footnotetext{
1 Disponível em : https://sites.google.com/site/siseuler/download.Acesso em Junho 2016. Junho 2016.

Disponível em : http://author.aumentaty.com/acerca-de-aumentaty-author?qt-info=1\#qt-info. Acesso em

3 Disponível em: http://artoolkit.org/ Acesso em Junho 2016.

Disponível em: https://unity3d.com/pt Acesso em Junho 2016.

Disponível em: https://www.blender.org/ Acesso em Junho 2016.

Disponível em: http://hiperrealidade.com.br/home/index.php?option=com content\&task=view\&id=38\&Itemid=54 Acesso em Junho 2016.
} 